\title{
Phylogenetic Relationships between Some Members of the Genera Neisseria, Acinetobacter, Moraxella, and Kingella Based on Partial 16S Ribosomal DNA Sequence Analysis
}

\author{
M. C. ENRIGHT, ${ }^{*}$ P. E. CARTER, I. A. MACLEAN, AND H. McKENZIE \\ Department of Medical Microbiology, Faculty of Medicine, University of Aberdeen,
} Foresterhill, Aberdeen, Scotland AB9 2ZD

\begin{abstract}
We obtained 16S ribosomal DNA (rDNA) sequence data for strains belonging to 11 species of Proteobacteria, including the type strains of Kingella kingae, Neisseria lactamica, Neisseria meningitidis, Moraxella lacunata subsp. lacunata, [Neisseria] ovis, Moraxella catarrhalis, Moraxella osloensis, [Moraxella] phenylpyruvica, and Acinetobacter lwoffii, as well as strains of Neisseria subflava and Acinetobacter calcoaceticus. The data in a distance matrix constructed by comparing the sequences supported the proposal that the genera Acinetobacter and Moraxella and $[N$.] ovis should be excluded from the family Neisseriaceae. Our results are consistent with hybridization data which suggest that these excluded taxa should be part of a new family, the Moraxellaceae. The strains that we studied can be divided into the following five groups: (i) $M$. lacunata subsp. lacunata, [N.] ovis, and $M$. catarrhalis; (ii) M. osloensis; (iii) [M.] phenylpyruvica; (iv) A. calcoaceticus and A. lwoffii; and (v) N. meningitidis, $N$. subflava, $N$. lactamica, and $K$. kingae. We agree with the previous proposal that $[N$.$] ovis should be renamed$ Moraxella ovis, as this organism is closely related to Moraxella species and not to Neisseria species. The generically misnamed taxon [M.] phenylpyruvica belongs to the proposed family Moraxellaceae, but it is sufficiently different to warrant exclusion from the genus Moraxella. Further work needs to be done to investigate genetically similar species, such as Psychrobacter immobilis, before the true generic position of this organism can be determined. Automated 16S rDNA sequencing with the PCR allows workers to accurately determine phylogenetic relationships between groups of organisms. This method is quicker and less complex than nucleic acid hybridization, produces similar results, and has the advantage that $16 \mathrm{~S}$ rDNA sequence information for different species can be directly compared.
\end{abstract}

The family Neisseriaceae was considered by Bøvre in 1984 (3) to consist of the genera Neisseria, Kingella, Acinetobacter, and Moraxella, the latter genus containing the subgenera Moraxella (rod-shaped bacteria) and Branhamella (cocci) (2). Since then it has been proposed that the genera Psychrobacter (10), Mesophilobacter (12), Alysiella (14), Eikenella, and Simonsiella (7) should also be included in this family.

In 1988 Stackebrandt et al. proposed the formation of a new class, the Proteobacteria, comprising the "purple bacteria and their relatives" (19). This class contains four subclasses, the $\alpha$, $\beta, \gamma$, and $\delta$ subclasses, which are distinguished on the basis of $16 \mathrm{~S}$ rRNA sequence similarities. The $\alpha, \beta$, and $\gamma$ subclasses correspond to rRNA superfamily IV, rRNA superfamily III, and rRNA superfamilies I and II of De Ley et al. $(6,13,16)$; the latter was distinguished by using rRNA-DNA hybridization data. In a study in which DNA-rRNA and DNA-DNA hybridization techniques were used, Rossau et al. (14) proposed that the genera Acinetobacter, Moraxella, and Psychrobacter should be removed from the Neisseriaceae as they belong to rRNA superfamily II ( $\gamma$ subclass) and species belonging to these genera exhibit low levels of rRNA-DNA and DNA-DNA hybridization with members of the genera Neisseria, Kingella, Eikenella, Simonsiella, and Alysiella. Species belonging to the latter genera exhibit high levels of rRNA similarity (the melting temperatures of elution are between 74 and $81^{\circ} \mathrm{C}$ ) and belong to rRNA superfamily III ( $\beta$ subclass of the Proteobacteria). Rossau et al. (15) proposed that the excluded genera should be placed in a new family, the Moraxellaceae, comprising two groups based on rRNA-DNA hybridization data. The Acinetobacter strains form one group, and the other group is

* Corresponding author. made up of the following four subgroups: (i) the authentic Moraxella strains, including Moraxella catarrhalis and the "false neisseriae"; (ii) Moraxella osloensis; (iii) Moraxella atlantae; and (iv) a [Moraxella] phenylpyruvica-Psychrobacter subgroup. However, Catlin proposed the formation of a different family, the Branhamaceae, to include the genera Moraxella and Branhamella (5).

Eleven species have been placed in the genus Neisseria, including the "true neisseriae" and four species incertae sedis (Neisseria animalis and the so-called false neisseriae, [Neisseria] caviae, [Neisseria] ovis, and [Neisseria] cuniculi) (21). Veron et al. (22) concluded from DNA-DNA hybridization and fatty acid analysis data that the false neisseriae form three separate genomic species which should be placed in the $\gamma$ subclass of the Proteobacteria and thus excluded from the family Neisseriaceae.

TABLE 1. Strains sequenced and their accession numbers

\begin{tabular}{|c|c|c|}
\hline Taxon & Strain & $\begin{array}{c}\text { EMBL } \\
\text { accession } \\
\text { no. }\end{array}$ \\
\hline M. catarrhalis & NCTC $11020^{\mathrm{T}}\left(=\operatorname{ATCC} 25238^{\mathrm{T}}\right)$ & X74903 \\
\hline $\begin{array}{l}\text { M. lacunata subsp. } \\
\text { lacunata }\end{array}$ & NCTC $11011^{\mathrm{T}}\left(=\operatorname{ATCC} 17967^{\mathrm{T}}\right)$ & X74895 \\
\hline$[N$.$] ovis$ & $\operatorname{NCTC} 11227^{\mathrm{T}}\left(=\operatorname{ATCC} 11227^{\mathrm{T}}\right)$ & X74896 \\
\hline M. osloensis & NCTC $10465^{\mathrm{T}}\left(=\right.$ ATCC $\left.19976^{\mathrm{T}}\right)$ & X74897 \\
\hline [M.] phenylpyruvica & NCTC $10526^{\mathrm{T}}\left(=\right.$ ATCC $\left.23333^{\mathrm{T}}\right)$ & X74898 \\
\hline A. calcoaceticus & NCTC 10292 & X74899 \\
\hline A. lwoffii & NCTC $05866^{\mathrm{T}}\left(=\right.$ ATCC $\left.15309^{\mathrm{T}}\right)$ & X74894 \\
\hline N. meningitidis & NCTC $10025^{\mathrm{T}}\left(=\right.$ ATCC $\left.13077^{\mathrm{T}}\right)$ & X74900 \\
\hline$K$ kingae & NCTC $10529^{\mathrm{T}}\left(=\right.$ ATCC $\left.23330^{\mathrm{T}}\right)$ & X74902 \\
\hline N. lactamica & NCTC $10617^{\mathrm{T}}\left(=\right.$ ATCC $\left.23970^{\mathrm{T}}\right)$ & X74901 \\
\hline N. subflava & NCTC 04590 & X74893 \\
\hline
\end{tabular}


TABLE 2. Primers used for $16 \mathrm{~S}$ rDNA sequencing $\left(5^{\prime}-3^{\prime}\right)$

\begin{tabular}{|c|c|}
\hline Primer & Sequence \\
\hline $\begin{array}{l}\text { Po } \ldots . . \\
\text { Pc3... } \\
\text { pD .... } \\
\text { pD }^{0} . . \\
\text { pC.... } \\
\text { pC }^{0} . .\end{array}$ & $\begin{array}{l}\text { GATC } \\
\text { CCAGGGTATCTAAT } \\
\text { CGCGGTAATAC } \\
\text { CGCGGCTGCTG } \\
\text { CTGGCAGCAGTGGG } \\
\text { CTGCTCCCGTAG }\end{array}$ \\
\hline
\end{tabular}

Catlin included these species in the genus Branhamella in the family Branhamaceae (5). In this study we used $16 \mathrm{~S}$ ribosomal DNA (rDNA) sequencing to examine the relationships among some species belonging to the $\beta$ subclass of the Proteobacteria (Kingella kingae, Neisseria lactamica, Neisseria meningitidis, Neisseria subflava) and to the $\gamma$ subclass (Moraxella lacunata subsp. lacunata, [N.] ovis, M. catarrhalis, M. osloensis, [M.] phenylpyruvica, Acinetobacter calcoaceticus, and Acinetobacter lwoffii).

\section{MATERIALS AND METHODS}

Bacterial strains. All of the strains used (Table 1) were obtained from the National Collection of Type Cultures, Public Health Laboratory Service, London, United Kingdom.

Culture conditions and DNA extraction. Organisms were inoculated onto Columbia agar plates containing 5\% horse blood (Oxoid) and incubated overnight at $37^{\circ} \mathrm{C}$ in the presence of $5 \% \mathrm{CO}_{2}$. DNA was extracted by using a variation of the method of Bjorvatn et al. (1). Fresh overnight growth was harvested and resuspended in $300 \mu \mathrm{l}$ of $10 \mathrm{mM}$ Tris (pH 8.0)-2 mM EDTA. To this preparation we added $100 \mu l$ of lysozyme $\left(50 \mathrm{mg} \mathrm{ml}{ }^{-1}\right), 10 \mu l$ of RNase $A\left(1 \mathrm{mg} \mathrm{ml}^{-1}\right), 10 \mu \mathrm{l}$ of proteinase $\mathrm{K}\left(5 \mathrm{mg} \mathrm{ml}^{-1}\right)$, and $300 \mu \mathrm{l}$ of a solution containing $10 \mathrm{mM}$ EDTA, $2 \%$ Triton $\mathrm{X}-100$, and $50 \mathrm{mM}$ Tris (pH 8.0), and the samples were mixed by inversion and then incubated for $30 \mathrm{~min}$ at $37^{\circ} \mathrm{C}$. Samples were extracted once with phenol and once with phenol-chloroform-isoamyl alcohol $(25: 24: 1)$. DNA was precipitated with ethanol at $-20^{\circ} \mathrm{C}$ and collected by centrifugation. The ethanol was removed, and the pellet was resuspended in $10 \mathrm{mM}$ Tris ( $\mathrm{pH} \mathrm{8.0)-2} \mathrm{mM} \mathrm{EDTA} \mathrm{to} \mathrm{a} \mathrm{final}$ DNA concentration of $20 \mathrm{ng} \mu \mathrm{l}^{-1}$.

PCR. The 16S rDNA template was amplified by using the method of Saiki et al. (17). The universal primers used for amplification of the $5^{\prime}$ ends of eubacterial $16 \mathrm{~S}$ rDNA genes, Po and Pc3 (23), were synthesized with an Applied Biosystems model 391 DNA synthesizer and were purified by using OPC columns (ABI, Warrington, United Kingdom). Amplification reaction mixtures $(50 \mu \mathrm{l})$ containing genomic DNA (2 ng $\left.\mu l^{-1}\right)$, both primers $(0.25 \mu \mathrm{M}$ each $)$, four deoxyribonucleotides

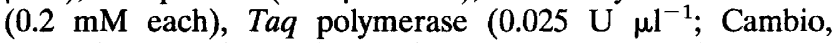
Cambridge, United Kingdom), and buffer containing Taq polymerase were heated at $94^{\circ} \mathrm{C}$ for $4 \mathrm{~min}$. This was followed by 25 cycles of denaturation at $94^{\circ} \mathrm{C}$ for $1 \mathrm{~min}$, annealing at $40^{\circ} \mathrm{C}$ for $1 \mathrm{~min}$, and extension at $72^{\circ} \mathrm{C}$ for $1.5 \mathrm{~min}$. The PCR products $(5 \mu \mathrm{l})$ were characterized by electrophoresis on $1 \%$ agarose gels and were visualized under UV light after they were stained with a solution containing $10 \mu \mathrm{g}$ of ethidium bromide per $\mu$ l.

DNA sequencing. Amplification products from the PCR were sequenced directly by using an Applied Biosystems model 373A automated DNA sequencer. PCR samples which produced a single band on agarose gels were purified for sequencing by using Centricon C-100 columns (Amicon, Gloucester, United Kingdom). Approximately $150 \mathrm{ng}$ of template was sequenced by using a Taq dye deoxy terminator sequencing kit (ABI) and the protocol recommended by the manufacturer. The primers used for sequencing are shown in Table $2(8,23)$.

\section{RESULTS}

Amplification of genomic DNA with universal 16S rRNA primers $P o$ and $P c 3$ resulted in a single 750-bp band on agarose gels. DNAs from 11 members of the genera Moraxella, Neisseria, Acinetobacter, and Kingella were amplified, and the fragments were sequenced by using the six primers shown in Table 2. At each position the nucleotides on both strands were determined to ensure correct base assignment. The sequences have been deposited in the GenBank and EMBL sequence data bases under the accession numbers shown in Table 1 . The sequences were aligned and compared by using the Clustal V suite of programs (9). The sequences which we obtained were between 712 and 743 bp long, and the $5^{\prime}$ end was located at position 44 in the Escherichia coli numbering system (4).

To quantify the relationships between species, the aligned DNA sequences were used to produce a distance matrix for pairs of sequences (Table 3 ) by using the neighbor-joining method of Saitou and Nei (18). A tree was produced from

TABLE 3. Distance matrix showing levels of homology between species, based on partial 16S rDNA sequences

\begin{tabular}{|c|c|c|c|c|c|c|c|c|c|c|}
\hline \multirow[b]{2}{*}{ Strain } & \multicolumn{10}{|c|}{$\%$ Homology with: } \\
\hline & 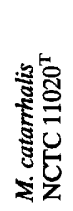 & 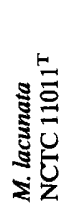 & 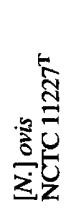 & 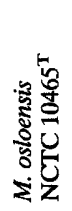 & 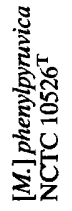 & 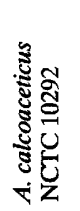 & 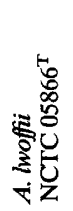 & 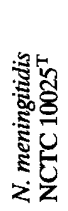 & 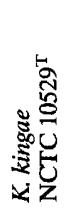 & 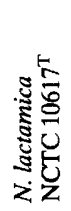 \\
\hline M. lacunata NCTC $11011^{\mathrm{T}}$ & 94.6 & & & & & & & & & \\
\hline$[N$.$] ovis NCTC 11227^{\mathrm{T}}$ & 94.9 & 94.8 & & & & & & & & \\
\hline M. osloensis NCTC $10465^{\mathrm{T}}$ & 90.1 & 90.1 & 90.1 & & & & & & & \\
\hline$[M$.$] phenylpyruvica NCTC 10526^{\mathrm{T}}$ & 89.7 & 89.3 & 88.2 & 89.8 & & & & & & \\
\hline A. calcoaceticus NCTC 10292 & 87.6 & 87.2 & 87.2 & 85.3 & 86.5 & & & & & \\
\hline A. lwoffii NCTC $05866^{\mathrm{T}}$ & 87.7 & 87.7 & 87.0 & 85.4 & 86.2 & 95.6 & & & & \\
\hline N. meningitidis NCTC $10025^{\mathrm{T}}$ & 81.2 & 82.1 & 81.2 & 79.7 & 80.6 & 81.8 & 80.4 & & & \\
\hline$K$ kingae NCTC $10529^{\mathrm{T}}$ & 81.3 & 80.5 & 80.8 & 78.4 & 79.2 & 80.4 & 79.0 & 92.3 & & \\
\hline N. lactamica NCTC $10617^{\mathrm{T}}$ & 80.8 & 80.3 & 80.1 & 79.2 & 79.0 & 80.7 & 81.0 & 93.5 & 91.0 & \\
\hline N. subflava NCTC 04590 & 81.8 & 81.1 & 81.3 & 80.3 & 80.7 & 80.8 & 80.3 & 95.5 & 91.2 & 94.2 \\
\hline
\end{tabular}




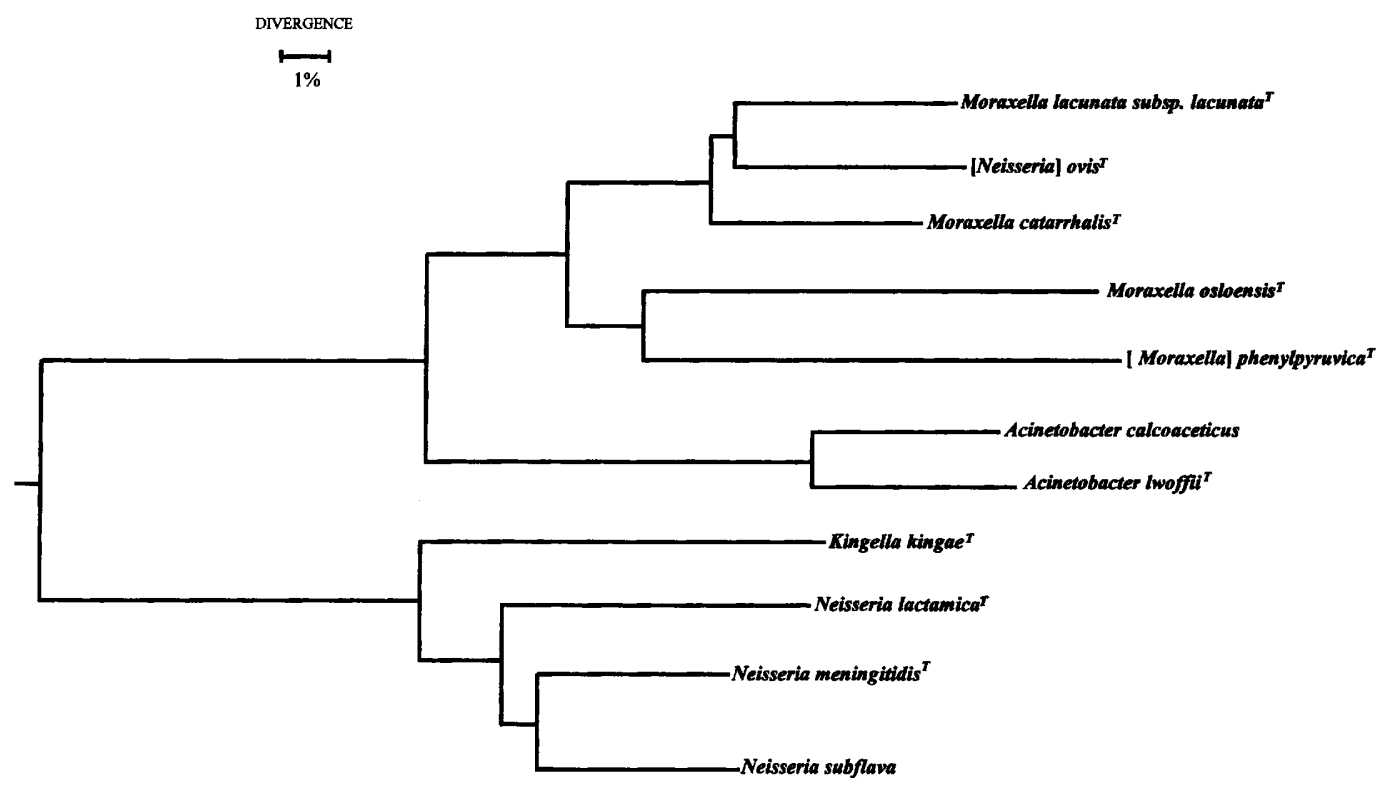

FIG. 1. Rooted phylogenetic tree. Horizontal distances are equivalent to genetic distances; vertical distances have no meaning.

these data, and the tree illustrates the relationships between species based on genetic distances (Fig. 1). The tree was rooted at the midpoint of its longest branch. All of the species used in this study fell into one of two large groups on the tree. The upper group included $M$. lacunata subsp. lacunata, $[N$.] ovis, $M$. catarrhalis, $M$. osloensis, $[M$.$] phenylpyruvica, A$. calcoaceticus, and $A$. lwoffii, and the lower group included $K$ kingae, $N$. lactamica, $N$. meningitidis, and $N$. subflava. The levels of sequence homology between members of the two groups varied from $78.4 \%$ ( $M$. osloensis and $K$. kingae) to $82.1 \%$ ( $M$. lacunata subsp. lacunata and $N$. meningitidis).

$M$. lacunata subsp. lacunata, $[N$.$] ovis, and M$. catarrhalis formed a tight cluster on the dendrogram (the $M$. lacunata cluster), with levels of DNA homology of at least $94.6 \%$. $M$. osloensis and $[M$.$] phenylpyruvica exhibited lower levels of$ homology with members of this cluster (90.1 and 88.2 to $89.7 \%$, respectively) and with each other $(89.8 \%)$. The two Acinetobacter species were more closely related to each other (95.6\% homology) than to members of the $M$. lacunata cluster (87.0 to $87.7 \%$ homology), $M$. osloensis (85.3 to $85.4 \%$ homology), or $[M$.] phenylpyruvica ( 86.2 to $86.5 \%$ homology). In the Neisseria group the true neisseriae were more closely related to each other ( 93.5 to $95.5 \%$ homology) than to $K$. kingae ( 91.0 to $92.3 \%$ homology), and the levels of DNA homology between $N$. meningitidis and $N$. subflava were slightly higher than the levels of homology between $N$. meningitidis and $N$. lactamica.

In addition to the sequences of the 11 isolates described above, the sequences of four clinical isolates of $M$. catarhalis obtained from Scotland, Belgium, Australia, and South Africa were also determined. These isolates exhibited very high levels of DNA homology with the type strain (99.8 to 100\%) (data not shown).

\section{DISCUSSION}

rDNA sequencing is the most useful tool for studying bacterial evolution because the sequences of the genes involved are subject to different rates of change. This means that sequence comparisons can be used to measure the relationship between distant or close relatives (24). 16S rDNA is the most widely studied of the ribosomal genes as it contains sufficient information to accurately determine most phylogenetic relationships up to about the species level (11). We used an automatic DNA sequencer and the PCR (8) to sequence approximately one-half of the $16 \mathrm{~S}$ rDNAs from 11 species belonging to the Proteobacteria.

Relationship between the Neisseria-Kingella group and the Moraxella-Acinetobacter group. DNA-DNA and rRNA-DNA hybridization studies of species belonging to the Neisseriaceae led to the proposal that the genera Moraxella, Acinetobacter, and Psychrobacter should be excluded from this family (14) and should instead be placed in a new family, the Moraxellaceae (15). We found little genetic similarity between members of the emended family Neisseriaceae and members of the proposed family Moraxellaceae. Our sequence data indicate that on the basis of rRNA sequence signatures (19), the true Neisseria species and $K$. kingae belong to the $\beta$ subclass of the Proteobacteria, whereas the genera Moraxella (including $[N$.] ovis) and Acinetobacter belong to the $\gamma$ subclass. We support the proposal of Rossau et al. (15) that [N.] ovis should be renamed Moraxella ovis as it is very closely related to other Moraxella species and is only distantly related to members of the Neisseriaceae.

Moraxella-Acinetobacter group. We placed the Acinetobacter and Moraxella species which we studied into the following four groups: (i) Acinetobacter species; (ii) the M. lacunata cluster, comprising $M$. catarrhalis, $M$. lacunata subsp. lacunata, and $[N$.] ovis; (iii) $M$. osloensis; and (iv) $[M$.] phenylpyruvica. These results are consistent with the results of other workers obtained by using rRNA-DNA and DNA-DNA hybridization methods $(15,22)$. Catlin (5) proposed that the genus Acinetobacter should be removed from the same family as the genus Moraxella because of phenotypic differences and a lack of phylogenetic evidence. Fatty acid analysis and rDNA-DNA hybridization results (22) suggested that there is a close relationship between the genera Moraxella and Acinetobacter, which was confirmed by our data. We therefore agree with Rossau et al. (15) and Veron et al. (22) that the genus Acinetobacter should be placed in the same family as the genus 
Moraxella despite the small phenotypic differences discussed by Catlin (5).

$M$. osloensis forms a separate group within the Moraxellaceae according to our data and the hybridization results of Rossau et al. (15). Rossau et al. proposed that this species should be removed from the genus Moraxella on the basis of their results, but a recent report (20) confirmed that $M$. osloensis is a genuine member of the genus Moraxella as it has melting temperatures of elution (as determined by rRNA-DNA hybridization) similar to those of a new Moraxella species, Moraxella lincolnii. $M$. osloensis and $M$. lincolnii have melting temperature of elution differences of less than $5^{\circ} \mathrm{C}$, which, together with the phenotypic similarities between $M$. osloensis and other members of the genus, suggests that $M$. osloensis is a genuine member of the genus Moraxella. $[M$.$] phenylpyruvica$ is not as closely related to the $M$. lacunata group as $M$. osloensis is but is more closely related than either of the Acinetobacter species is. Rossau et al. (15) expressed doubts concerning whether this organism should be placed in the genus Moraxella as it is closely related to Psychrobacter immobilis genotypically but is not a member of this species on the basis of the results of transformation studies (10). We agree with Rossau et al. that this species should be placed in the Moraxellaceae on the basis of phylogenetic and phenotypic data, but there is little evidence to keep this species in the genus Moraxella. Further study of $P$. immobilis will be required to establish the taxonomic position of $[M$.$] phenylpyruvica.$

Neisseria-Kingella group. We found that the true neisseriae and $K$. kingae belong to the $\beta$ subclass of the Proteobacteria on the basis of $16 \mathrm{~S}$ rDNA sequence data (19). These organisms form a cluster with DNA homology values of $\geq 91.0 \%$. $N$. meningitidis $16 \mathrm{~S}$ rDNA exhibits a slightly higher level of sequence identity with $N$. subflava DNA than with $N$. lactamica DNA. These results are in contrast to the findings of Rossau et al. (14), who, on the basis of DNA-DNA hybridization results, suggested that $N$. lactamica and $N$. meningitidis are members of a subgroup distinct from $N$. subflava. Our results could be explained by the fact that we used a different strain of $N$. subflava (NCTC 04590) than Rossau et al. used (ATCC 10555).

Using the PCR and an automated DNA sequencer, we sequenced about one-half of the $16 \mathrm{~S}$ rDNAs of 11 bacterial species. Our results are in general agreement with the results found in similar phylogenetic studies in which hybridization techniques were used, but the 16S rDNA sequencing approach has the advantage that sequences, which are deposited in the GenBank and EMBL data bases, can be compared quickly with sequences of any other bacteria. The speed and simplicity of automated $16 \mathrm{~S}$ rDNA sequencing are comparable to the speed and simplicity of hybridization methods.

\section{ACKNOWLEDGMENTS}

We are very grateful to $\mathrm{H}$. Pennington and $\mathrm{K}$. Forbes for reading the manuscript.

This work was funded by the Clinical and Biomedical Research Committee of the Scottish Home and Health Department.

\section{REFERENCES}

1. Bjorvatn, B., V. Lund, B. K. Kristiansen, L. Korsnes, O. Spanne, and B. Lindquist. 1984. Applications of restriction endonuclease fingerprinting of chromosomal DNA of Neisseria meningitidis. J. Clin. Microbiol. 19:763-765.

2. Bøvre, K. 1979. Proposal to divide the genus Moraxella Lwoff 1939 emend. Henriksen and Bøvre 1968 into two subgenera, subgenus Moraxella (Lwoff 1939) Bøvre 1979 and subgenus Branhamella (Catlin 1970) Bøvre 1979. Int. J. Syst. Bacteriol. 29:403-406.

3. Bøvre, K. 1984. Neisseriaceae Prevot 1933, 119 AL, p. 288-290. In
N. R. Krieg and J. G. Holt (ed.), Bergey's manual of systematic bacteriology, vol. 1. The Williams \& Wilkins Co., Baltimore.

4. Brosius, J., J. L. Palmer, J. P. Kennedy, and H. F. Noller. 1978. Complete nucleotide sequence of a $16 \mathrm{~S}$ ribosomal RNA gene from Escherichia coli. Proc. Natl. Acad. Sci. USA 75:4801-4805.

5. Catlin, B. W. 1991. Branhamaceae fam. nov., a proposed family to accommodate the genera Branhamella and Moraxella. Int. J. Syst. Bacteriol. 41:320-323.

6. De Ley, J. 1978. Modern molecular methods in bacterial taxonomy: evaluation, application, prospects, p. 347-357. In Proceedings of the 4th International Conference on Plant Pathogenic Bacteria, vol. 1. Gibert-Clarey, Tours, France.

7. Dewhirst, F. E., B. J. Paster, and P. L. Bright. 1989. Chromobacterium, Eikenella, Kingella, Neisseria, Simonsiella, and Vitreoscilla species comprise a major branch of the beta group Proteobacteria by $16 \mathrm{~S}$ ribosomal ribonucleic acid sequence comparison: transfer of Eikenella and Simonsiella to the family Neisseriaceae (emend.). Int. J. Syst. Bacteriol. 39:258-266.

8. Edwards, U., T. Rogall, H. Blocker, M. Emde, and E. C. Bottger. 1989. Isolation and direct complete nucleotide determination of entire genes. Characterization of a gene coding for $16 \mathrm{~S}$ ribosomal RNA. Nucleic Acids Res. 17:7843-7853.

9. Higgins, D. G., A. J. Bleasby, and R. Fuchs. 1992. CLUSTAL V: improved software for multiple sequence alignment. CABIOS 8:189-191.

10. Juni, E., and G. A. Heym. 1986. Psychrobacter immobilis gen. nov., sp. nov.: genospecies composed of gram-negative, aerobic, oxidase-positive coccobacilli. Int. J. Syst. Bacteriol. 36:388-391.

11. Murray, R. G. E., D. J. Brenner, R. R. Colwell, P. De Vos, M. Goodfellow, P. A. D. Grimont, N. Pfennig, E. Stackebrandt, and G. A. Zavarzin. 1990. Report of the Ad Hoc Committee on Approaches to Taxonomy within the Proteobacteria. Int. J. Syst. Bacteriol. 40:213-215.

12. Nishimura, Y., M. Kinpara, and H. Iizuka. 1989. Mesophilobacter marinus gen. nov., sp. nov.: an aerobic coccobacillus isolated from seawater. Int. J. Syst. Bacteriol. 39:378-381.

13. Rossau, R., K. Kersters, E. Falsen, E. Jantzen, P. Segers, A. Union, L. Nehls, and J. De Ley. 1987. Oligella, a new genus including Oligella urethralis comb. nov. (formerly Moraxella urethralis) and Oligella ureolytica sp. nov. (formerly CDC group IVe): relationship to Taylorella equigenitalis and related taxa. Int. J. Syst. Bacteriol. 37:198-210.

14. Rossau, R., G. Vandenbussche, S. Thielemans, P. Segers, H. Grosch, E. Gothe, W. Mannheim, and J. De Ley. 1989. Ribosomal ribonucleic acid cistron similarities and deoxyribonucleic acid homologies of Neisseria, Kingella, Eikenella, Simonsiella, Alysiella, and Centers for Disease Control groups EF-4 and M-5 in the emended family Neisseriaceae. Int. J. Syst. Bacteriol. 39:185198.

15. Rossau, R., A. Van Landschoot, M. Gillis, and J. De Ley. 1991. Taxonomy of Moraxellaceae fam. nov., a new bacterial family to accommodate the genera Moraxella, Acinetobacter, and Psychrobacter and related organisms. Int. J. Syst. Bacteriol. 41:310319.

16. Rossau, R., A. Van Landschoot, W. Mannheim, and J. De Ley. 1986. Inter- and intragenic similarities of ribosomal ribonucleic acid cistrons of the Neisseriaceae. Int. J. Syst. Bacteriol. 36:323332.

17. Saiki, R. K., D. H. Gelfand, S. Stoffel, S. J. Scharf, R. Higuchi, G. T. Horn, K. B. Mullis, and H. A. Ehrlich. 1988. Primer-directed enzymatic amplification of DNA with a thermostable DNA polymerase. Science 239:487-491.

18. Saitou, N., and M. Nei. 1987. The neighbour-joining method: a new method for reconstructing phylogenetic trees. Mol. Biol. Evol. 4:406-425.

19. Stackebrandt, E., R. G. E. Murray, and H. G. Trüper. 1988. Proteobacteria classis nov., a name for the phylogenetic taxon that includes the "purple bacteria and their relatives." Int. J. Syst. Bacteriol. 38:321-325.

20. Vandamme, P., M. Gillis, M. Vancanneyt, B. Hoste, K. Kersters, and E. Falsen. 1993. Moraxella lincolnii sp. nov., isolated from the human respiratory tract, and reevaluation of the taxonomic position of Moraxella osloensis. Int. J. Syst. Bacteriol. 43:474-481. 
21. Vedros, N. A. 1984. Genus I. Neisseria Trevisan $1885,105^{\mathrm{AL}}$, p. 290-296. In N. R. Krieg and J. G. Holt (ed.), Bergey's manual of systematic bacteriology, vol. 1. The Williams \& Wilkins Co., Baltimore.

22. Veron, M., A. Lenvoise-Furet, C. Coustere, C. Ged, and F. Grimont. 1993. Relatedness of three species of "false Neisseria," Neisseria caviae, Neisseria cuniculi, and Neisseria ovis, by DNA-
DNA hybridizations and fatty acid analysis. Int. J. Syst. Bacteriol. 43:210-220.

23. Wilson, K. H., R. B. Blitchington, and R. C. Greene. 1990. Amplification of bacterial 16S ribosomal DNA with polymerase chain reaction. J. Clin. Microbiol. 28:1942-1946.

24. Woese, C. R. 1987. Bacterial evolution. Microbiol. Rev. 51:221271. 